\title{
CARACTERIZAÇÃO DE CULTIVARES DE COFFEA ARABICA MEDIANTE UTILIZAÇÃO DE DESCRITORES MÍNIMOS ${ }^{(1)}$
}

\author{
ADRIANO TOSONI DA EIRA AGUIAR ${ }^{(2,5)}$; OLIVEIRO GUERREIRO-FILHO ${ }^{(2,6)}$, \\ MIRIAN PEREZ MALUF ${ }^{(3)}$; PAULO BOLLER GALLO ${ }^{(4)}$; LUIZ CARLOS FAZUOLI ${ }^{(2,6)}$
}

\begin{abstract}
RESUMO
Cerca de $70 \%$ do café produzido e comercializado mundialmente é oriundo de Coffea arabica. A espécie apresenta base genética estreita sendo as cultivares bastante aparentadas e originárias em sua maioria das tradicionais cultivares Típica e Bourbon. Este trabalho foi desenvolvido com o objetivo de identificar a eficiência de descritores mínimos na caracterização de cultivares de cafeeiros e como diferenciadores entre cultivares a serem submetidas ao processo de proteção de cultivares no Brasil. Foram avaliadas trinta e oito características botânicas ou tecnológicas das plantas, folhas, flores, frutos, sementes, assim como três características agronômicas. Utilizaram-se vinte e nove cultivares de cafeeiros selecionadas pelo Instituto Agronômico, sendo avaliadas trinta plantas de cada cultivar. Os resultados evidenciaram que apenas com a utilização das características porte, cor do fruto, resistência ao agente da ferrugem, Hemileia vastatrix e ciclo de maturação é possível obter uma discriminação eficiente dos diferentes grupos de cultivares avaliadas. A cor das folhas jovens e o diâmetro da copa revelaram-se importantes descritores na discriminação de cultivares do grupo Mundo Novo. Não foi possível, porém, identificar descritores eficientes na discriminação das cultivares dos grupos Catuaí Vermelho, Catuaí Amarelo e Icatu Vermelho.
\end{abstract}

Palavras-chave: base genética, café, DHE, proteção de cultivares.

\section{ABSTRACT \\ CHARACTERIZATION OF COFFEA ARABICA CULTIVARS BY MINIMUM DESCRIPTORS}

The species Coffea arabica is responsible for $70 \%$ of the world coffee production. The majority of cultivars has a narrow genetic origin, being derived basically from two old cultivars: Tipica and Bourbon. This investigation was carried out aiming at the characterization of selected cultivars of the Instituto Agronomico according to standard descriptors. Thirty five morphological or technological traits of canopy, leaves, flowers, fruits or seeds and three agronomic traits were evaluated in twenty nine cultivar lines of the current breeding program. The variables plant height, fruit color, leaf rust resistance and earliness are sufficient for an efficient identification of groups of cultivars. The color of young leaves and plant diameter are important descriptors for discriminating cultivars of the Mundo Novo group, but they could not identify cultivars of the Catuaí Vermelho, Catuaí Amarelo and Icatu Vermelho groups.

Key words: coffee, breeder's right, DUS, cultivar protection.

${ }^{1}$ ) Trabalho parcialmente financiado pelo Consórcio Brasileiro de Pesquisas Cafeeiras. Parte da dissertação de mestrado do primeiro autor. Recebido para publicação em 14 de julho de 2003 e aceito em 7 de abril de 2004.

( ${ }^{2}$ ) Centro de Análise e Pesquisa Tecnológica do Agronegócio do Café “Alcides Carvalho". Instituto Agronômico, Caixa Postal 28, 13001-970, Campinas (SP). E-mail: oliveiro@iac.sp.gov.br

( ${ }^{3}$ ) Embrapa/Café

( $\left.{ }^{4}\right)$ Pólo Regional de Desenvolvimento Tecnológico dos Agronegócios do Nordeste Paulista, Mococa (SP).

$\left({ }^{5}\right)$ Com bolsa de Mestrado da FAPESP.

$\left({ }^{6}\right)$ Com bolsa de produtividade em pesquisa do CNPq. 


\section{INTRODUÇÃO}

O cafeeiro, uma das mais importantes espécies do mercado agrícola, tornou-se em 2000, espécie passível de proteção no Brasil. A legislação em vigor a partir dessa data permite a proteção para fins de exploração comercial de novas cultivares das espécies Coffea arabica, C. canephora e também de híbridos entre essas espécies, assim como de cultivares essencialmente delas derivadas.

Para tanto, é necessário que determinadas instruções (BRASIL, 2000), em parte comuns às diversas outras espécies já consideradas como passíveis de proteção e em parte específicas à cultura do cafeeiro, sejam devidamente atendidas. Assim, experimentos que possam comprovar a distinguibilidade, homogeneidade e estabilidade (DHE) de uma nova cultivar devem ser realizados mediante adoção de condições estabelecidas pela legislação, tais como número mínimo de dois ciclos de crescimento, apenas um local de avaliação e parcelas experimentais de tamanho suficiente para garantir as observações necessárias.

Os descritores mínimos para o registro institucional de cultivares do Instituto Agronômico (IAC) de Campinas (FAzuoli et al., 1994) e de descritores botânicos para identificação taxonômica de germoplasma de Coffea (IPGRI, 1996) serviram de base para a elaboração dos descritores mínimos visando à caracterização, identificação e discriminação de cultivares de café a serem utilizados nos experimentos de DHE. A relação oficial desses descritores, elaborada em parceria por instituições públicas de pesquisa - IAC, EPAMIG, IAPAR e INCAPER - encontra-se publicada no Diário Oficial da União, 2000.

Cerca de $70 \%$ da produção mundial de café é oriunda de cultivares de C. arabica, sendo praticamente a mesma proporção observada no Brasil. A espécie é nativa de uma região restrita e marginal às demais espécies do gênero, localizada no Sudoeste da Etiópia, Sudeste do Sudão e Norte do Quênia, entre 1.000 e 3.000 metros de altitude (CArvalho, 1946). Considerada alotetraplóide do tipo segmental $(2 n=4 x=44$ cromossomos), autocompatível, multiplica-se essencialmente por autofecundação.

As cultivares de $C$. arabica são bastante aparentadas e em grande maioria, derivam-se das cultivares Típica, originalmente introduzida no Brasil em 1727 e Bourbon Vermelho, oriunda da ilha de mesmo nome (ANTHONY et al., 2001). Embora a base genética da espécie seja bastante estreita (BERTHAUD e CHARRIER, 1988), as cultivares comercializadas apresentam grande variabilidade botânica oriunda de uma série de mutações e de cruzamentos naturais e artificiais realizados (KRUG et al., 1938).
Neste trabalho, avaliou-se a eficiência da utilização dos descritores mínimos estabelecidos para o cafeeiro na distinguibilidade de cultivares de $C$. arabica selecionadas pelo Instituto Agronômico (IAC), de Campinas, as quais representam cerca de $90 \%$ do parque cafeeiro nacional da espécie.

\section{MATERIAL -E MÉTODOS}

\subsection{Material}

Utilizou-se no estudo, as principais cultivares de $C$. arabica selecionadas pelo programa de melhoramento do cafeeiro desenvolvido pelo Instituto Agronômico (IAC). O germoplasma avaliado encontrase em experimentos de progênies presentes em campos experimentais localizados nas Fazendas Monte d'Este e Santa Elisa (Centro Experimental Central) do IAC ambas no município de Campinas (SP), no Pólo Regional de Desenvolvimento Tecnológico dos Agronegócios do Nordeste Paulista, em Mococa (SP) e na Fazenda Santo Antônio, em Pedregulho (SP).

A relação e o número de cultivares avaliadas são apresentados na tabela 1, sendo: Catuaí Vermelho (5), Catuaí Amarelo (5), Ouro Verde (1), Bourbon Amarelo (1), Mundo Novo (5), Acaiá (3), Obatã (1), Tupi (1), Icatu Vermelho (5), Icatu Precoce (1) e Icatu Amarelo (1).

\subsection{Metodologia}

No período de 1999 a 2001 foram avaliadas trinta e oito características, segundo a lista oficial de descritores mínimos para o café compreendendo características associadas às plantas (8) e órgãos como folhas (10), flores (4), frutos (5) e sementes (8). Paralelamente, foram avaliadas três características agronômicas: resistência ao agente da ferrugem (Hemileia vastatrix), ciclo de maturação dos frutos e ciclo até a primeira produção (Tabela 2).

As avaliações foram realizadas em trinta plantas de cada cultivar, as quais foram selecionadas com base em sua representatividade e produtividade.

As análises referentes às características das folhas tais como comprimento, largura, forma, cor das folhas jovens e adultas, ondulação das bordas, intensidade de ondulação, profundidade da nervura secundária e domácias foram realizadas em amostras de 90 folhas por cultivar - 30 folhas por repetição coletando-se ao acaso três folhas do quarto par de folhas de cada planta, a uma altura aproximada de $1 \mathrm{~m}$ do solo. 
Tabela 1. Relação de cultivares de C. arabica avaliadas e localização dos ensaios experimentais

\begin{tabular}{|c|c|c|}
\hline Cultivar & Local & Cidade \\
\hline Catuaí Vermelho IAC 44 & Fazenda Santo Antônio & Pedregulho \\
\hline Catuaí Vermelho IAC 46 & Fazenda Monte d`Este & Campinas \\
\hline Catuaí Vermelho IAC 81 & Fazenda Monte d’Este & Campinas \\
\hline Catuaí Vermelho IAC 99 & Fazenda Monte d`Este & Campinas \\
\hline Catuaí Vermelho IAC 144 & Fazenda Monte d’Este & Campinas \\
\hline Catuaí Amarelo IAC 47 & Fazenda Monte d’Este & Campinas \\
\hline Catuaí Amarelo IAC 62 & Fazenda Monte d’Este & Campinas \\
\hline Catuaí Amarelo IAC 74 & Fazenda Monte d’Este & Campinas \\
\hline Catuaí Amarelo IAC 86 & Pólo Regional do Nordeste Paulista & Mococa \\
\hline Catuaí Amarelo IAC 100 & Fazenda Monte d`Este & Campinas \\
\hline Ouro Verde IAC H5010-5 & Fazenda Monte d`Este & Campinas \\
\hline Bourbon Amarelo IAC J18 & Fazenda Monte d’Este & Campinas \\
\hline Mundo Novo IAC 376-4 & Pólo Regional do Nordeste Paulista & Mococa \\
\hline Mundo Novo IAC 379-19 & Fazenda Santa Elisa & Campinas \\
\hline Mundo Novo IAC 388-17 & Fazenda Monte d’Este & Campinas \\
\hline Mundo Novo IAC 501 & Fazenda Santa Elisa & Campinas \\
\hline Mundo Novo IAC 515 & Fazenda Santa Elisa & Campinas \\
\hline Acaiá IAC 474-4 & Fazenda Santa Elisa & Campinas \\
\hline Acaiá IAC 474-16 & Pólo Regional do Nordeste Paulista & Mococa \\
\hline Acaiá IAC 474-19 & Fazenda Monte d`Este & Campinas \\
\hline Obatã IAC 1669-20 & Pólo Regional do Nordeste Paulista & Mococa \\
\hline Tupi IAC 1669-33 & Fazenda Santa Elisa & Campinas \\
\hline Icatu Vermelho IAC 2945 & Fazenda Santo Antônio & Pedregulho \\
\hline Icatu Vermelho IAC 4040 & Pólo Regional do Nordeste Paulista & Mococa \\
\hline Icatu Vermelho IAC 4042 & Pólo Regional do Nordeste Paulista & Mococa \\
\hline Icatu Vermelho IAC 4045 & Fazenda Monte d`Este & Campinas \\
\hline Icatu Vermelho IAC 4046 & Fazenda Monte d’Este & Campinas \\
\hline Icatu Precoce IAC 3282 & Fazenda Santo Antônio & Pedregulho \\
\hline Icatu Amarelo IAC 2944-6 & Fazenda Monte d’Este & Campinas \\
\hline
\end{tabular}

As avaliações relacionadas ao número de inflorescência por axila e número de flores por inflorescência foram realizadas a partir de 90 contagens por cultivar - 30 contagens por repetição realizadas no quarto par de inflorescência de cada planta e a uma altura aproximada de $1 \mathrm{~m}$ do solo. A compatibilidade e a fertilidade do pólen foram observadas a partir de autofecundações realizadas em cada uma das trinta plantas da cultivar, considerando-se o número de flores dos ramos e o de frutos obtidos.

O tamanho, o formato e a coloração dos frutos maduros, assim como a presença de sépalas nos mesmos foram analisados em amostras de 90 frutos por cultivar - 30 frutos por repetição - coletando-se, ao acaso, três frutos na quarta roseta de ramos produtivos localizados a uma altura aproximada de $1 \mathrm{~m}$ do solo. O grau de aderência dos frutos aos ramos foi determinado na mesma amostra mediante utilização de um dinamômetro. As características de cor, comprimento, largura e espessura das sementes e a tonalidade e aderência da película prateada foram também determinadas em amostras de 90 sementes por cultivar - 30 sementes por repetição obtidas dos frutos coletados para avaliação. A massa de cem sementes foi também avaliada em três repetições, sendo as amostras obtidas a partir dos frutos coletados para análise. O mesmo material foi utilizado para dosagem do teor de cafeína em cromatografia líquida de alta eficiência (CLAE). 
Quanto às características agronômicas das plantas, o ciclo de maturação foi determinado a partir da contagem em dias do período compreendido entre a antese e a maturação completa dos frutos avaliada visualmente. $\mathrm{O}$ ciclo até a primeira produção após plantio foi obtido a partir do número do plantio à primeira colheita das plantas de cada cultivar. Finalmente, a resistência ao agente da ferrugem foi avaliada em condições de campo em período de alta incidência do patógeno.

Para efeito de análise foram estabelecidas diferentes classes para cada uma das características avaliadas e atribuindo-se a cada uma delas um número diferente de pontos - códigos - conforme relação de descritores mínimos elaborada para a cultura do cafeeiro (Brasil, 2000). A valoração dos 38 descritores foi realizada com base em avaliações prévias de cultivares usando para cada uma das características, cultivares-referência (Tabela 2).

\section{RESULTADOS E DISCUSSÃO}

As características qualitativas das plantas, folhas, flores, frutos e sementes de todas as cultivares analisadas são apresentadas nas tabelas 3, 4, 5 e 6.

\subsection{Plantas}

Com relação às características associadas às plantas, somente a altura das plantas, o comprimento dos internódios, o diâmetro da copa e a intensidade de ramificação plagiotrópica foram eficientes na discriminação das cultivares. Observa-se que exceto as cultivares do grupo Acaiá, com formato cilíndricocônico, as plantas das demais apresentam formato cilíndrico (Tabela 3). Trata-se de uma característica da espécie $C$. arabica determinada pelo crescimento proporcional dos ramos ortotrópico - haste - e plagiotrópicos. Cultivares de C. canephora, não avaliadas no presente estudo, são poliortotrópicos (FAZUOLI, 1986), característica que confere formato cônico invertido às plantas devido ao intenso crescimento vegetativo dos ponteiros e conseqüente envergamento das hastes para o exterior.

As cultivares de C. arabica apresentam, sem exceção, apenas uma haste de média flexibilidade e ramificação plagiotrópica do tipo horizontal. A intensidade da ramificação plagiotrópica é considerada alta para as cultivares Obatã IAC 1669-20, Tupi IAC 1669-33, Ouro Verde IAC H5010-5 e aquelas do grupo Catuaí Vermelho, média, para as cultivares dos grupos Mundo Novo e Icatu, baixa para a cultivar Bourbon Amarelo IAC J18 e as do grupo Acaiá.
Essa característica é importante critério de seleção no melhoramento do cafeeiro, pois se correlaciona com o potencial produtivo (correlação positiva) e com o porte das plantas (correlação negativa).

O crescimento dos cafeeiros é determinado, em sua grande magnitude, por um gene denominado $c a-$ turra (CARVAlHo et al., 1984), sendo sua utilização um marco importante para o melhoramento do cafeeiro no Brasil (CARvalHo e Mônaco, 1972), uma vez que o desenvolvimento de cultivares de porte baixo contribuiu sobremaneira para a redução do custo de produção das lavouras. Plantas $c t c t$ têm maior crescimento, enquanto plantas $C t C t$ ou $C t c t$ são menores e mais compactas e produtivas. As características altura da planta, diâmetro da copa e comprimento dos internódios são diretamente relacionadas à expressão desse gene e guardam importante correlação entre si, como se pode notar em avaliações realizadas com as diferentes cultivares.

As cultivares do grupo Mundo Novo (ct ct) foram classificadas como muito altas; Bourbon Amarelo IAC J18, Icatu Precoce IAC 3282 Icatu Amarelo IAC 2944-6 e as dos grupos Icatu Vermelho, e Acaiá (ct ct) como altas; as cultivares dos grupos Catuaí Vermelho, Catuaí Amarelo e a cultivar Ouro Verde IAC H5010-5 (Ct Ct) como médias e, finalmente, Tupi IAC 1669-33 e Obatã IAC 1669-20 (Ct $C t$ ), como baixas. Classificação semelhante foi observada em relação ao diâmetro da copa e ao comprimento dos internódios. Apesar das cultivares do grupo Mundo Novo serem classificadas como muito largas em relação ao diâmetro da copa, experimentos de campo evidenciam que a saia de cafeeiros de Mundo Novo IAC 388-17 é cerca de $20 \%$ mais larga do que as demais cultivares do mesmo grupo (CARVALHO et al., 1984).

Diferenças entre cultivares de mesmo genótipo para o caráter, como Ouro Verde IAC H5010-5 (Ct Ct) e Obatã IAC 1669-20 (Ct $C t)$ ou as cultivares do grupo Mundo Novo ( $c t c t$ ) e Bourbon Amarelo IAC J18 ( $c t$ $c t$ ), devem-se à expressão de outros genes menores relacionados também ao crescimento das plantas. É evidente que o desenvolvimento vegetativo das plantas tem também forte componente ambiental, podendo ser bastante influenciado por variações de temperatura, luminosidade, espaçamento de plantio, umidade, adubação, entre outras. Assim, cultivares de porte reduzido $(C t C t)$ podem, por exemplo, apresentar maior altura em relação à cultivares de porte normal (ct $c t)$ quando plantadas em regiões de clima mais quente e úmido, quando adubadas em maior proporção ou quando cultivadas em espaçamentos adensados. Devese salientar que nenhum desses descritores foi eficiente na discriminação entre cultivares de um mesmo grupo. 
Tabela 2. Características avaliadas, respectivas classes e códigos atribuídos segundo lista oficial de descritores mínimos para a cultura do cafeeiro

\begin{tabular}{|c|c|c|}
\hline Planta/orgão & Característica & Classes (códigos atribuídos) \\
\hline \multirow[t]{10}{*}{ Planta } & Formato & Cilíndrico (1); cônico (2); cilíndrico-cônico (3); cônico invertido (4) \\
\hline & Altura da planta & Muito baixa (1); baixa (3); média (5); alta (7); muito alta (9) \\
\hline & Diâmetro da copa & Muito pequeno (1); pequeno (3); médio (5); grande (7); muito grande (9) \\
\hline & Comprimento do internódio & Curto (3); médio (5); longo (7) \\
\hline & Ramificação plagiotrópica: tipo & Ereta (1); semi-ereta (2); horizontal (3); semipendente (4) \\
\hline & Ramificação plagiotrópica: intensidade & Baixa (3); média (5); alta (7) \\
\hline & Ramo ortotrópico: quantidade & Baixa (3); média (5); alta (7) \\
\hline & Ramo ortotrópico: flexibilidade & Baixa (3); média (5); alta (7) \\
\hline & Resistência a $H$. vastatrix & Ausente (1); presente (2) \\
\hline & Ciclo de maturação & Muito precoce (1); precoce (3); médio (5); tardio (7); muito tardio (9) \\
\hline \multirow[t]{11}{*}{ Folha } & Ciclo até $1^{a}$ produção após plantio & Precoce (3); médio (5); tardio (7) \\
\hline & Comprimento & Curto (3); médio (5); longo (7) \\
\hline & Largura & Estreita (3); média (5); larga (7) \\
\hline & Forma & Elíptica (1); ovalada (2); lanceolada (3) \\
\hline & Cor da folha jovem & Verde (1); bronze (2); verde e bronze (3); púrpura (4) \\
\hline & Cor da folha adulta & Verde-clara (1); verde-escura (2); púrpura (3) \\
\hline & Ondulação das bordas & Ausente (1); presente (9) \\
\hline & Intensidade de ondulação & Fraca (3); média (5); forte (7) \\
\hline & Profundidadeda nervura $2^{\text {ária }}$ & Baixa (3); média (5); alta (7) \\
\hline & Domácias & Ausente (1); parcialmente desenvolvida (2); bem desenvolvida (3) \\
\hline & Pubescência das domácias & Ausente (1); presente (9) \\
\hline \multirow[t]{4}{*}{ Flor } & Inflorescências / axila & Baixa (3); média (5); alta (7) \\
\hline & Flores/inflorescência & Baixa (3); média (5); alta (7) \\
\hline & Pólen & Fértil (1); estéril (2) \\
\hline & Compatibilidade & Autocompatível (1); parcialmente compatível (2); auto-incompatível (3) \\
\hline \multirow[t]{5}{*}{ Fruto } & Tamanho & Muito pequeno (1); pequeno (3); médio (5); grande (7); muito grande (9) \\
\hline & Formato & Redondo (1); elíptico (2); oblongo (3) \\
\hline & Cor & Amarela (1); vermelho-alaranjada (2); vermelho-média (3); vermelho-escura (4) \\
\hline & Sépala & Ausente (1); presente (2) \\
\hline & Grau aderência ao ramo & Baixo (3); médio(5); alto (7) \\
\hline \multirow[t]{8}{*}{ Semente } & Comprimento & Curto (3); médio (5); longo (7) \\
\hline & Largura & Estreita (3); média (5); larga (7) \\
\hline & Espessura & Fina (3); média (5); grossa (7) \\
\hline & Cor do endosperma & Amarela (1); verde (2) \\
\hline & Tonalidade da película prateada & Clara (1); escura (2) \\
\hline & Aderência da película prateada & Fraca (3); média (5); forte (7) \\
\hline & Teor de cafeína & Baixo (3); média (5); alto (7) \\
\hline & Massa de cem sementes & Baixa (3); média (5); alta (7) \\
\hline
\end{tabular}




\begin{tabular}{|c|c|c|c|c|c|c|c|c|}
\hline \multirow{2}{*}{ Cultivar } & \multirow{2}{*}{ Formato } & \multirow{2}{*}{$\begin{array}{c}\text { Altura } \\
\text { da planta }\end{array}$} & \multirow{2}{*}{$\begin{array}{l}\text { Diâmetro } \\
\text { da copa }\end{array}$} & \multirow{2}{*}{$\begin{array}{l}\text { Comprimento } \\
\text { do internódio }\end{array}$} & \multicolumn{2}{|c|}{ Ramificação plagiotrópica } & \multicolumn{2}{|c|}{ Ramo ortotrópico } \\
\hline & & & & & Tipo & Intensidade & Quantidade & Flexibilidade \\
\hline Acaiá IAC 474-4 & Cilindrocônico & Alta & Grande & Longo & Horizontal & Baixa & Baixa & Média \\
\hline Acaiá IAC 474-16 & Cilindrocônico & Alta & Grande & Longo & Horizontal & Baixa & Baixa & Média \\
\hline Acaiá IAC 474-19 & Cilindrocônico & Alta & Grande & Longo & Horizontal & Baixa & Baixa & Média \\
\hline Bourbon Amarelo IAC J18 & Cilíndrico & Alta & Grande & Longo & Horizontal & Baixa & Baixa & Média \\
\hline Catuaí Amarelo IAC 47 & Cilíndrico & Média & Médio & Médio & Horizontal & Alta & Baixa & Média \\
\hline Catuaí Amarelo IAC 62 & Cilíndrico & Média & Médio & Médio & Horizontal & Alta & Baixa & Média \\
\hline Catuaí Amarelo IAC 74 & Cilíndrico & Média & Médio & Médio & Horizontal & Alta & Baixa & Média \\
\hline Catuaí Amarelo IAC 86 & Cilíndrico & Média & Médio & Médio & Horizontal & Alta & Baixa & Média \\
\hline Catuaí Amarelo IAC 100 & Cilíndrico & Média & Médio & Médio & Horizontal & Alta & Baixa & Média \\
\hline Catuaí Vermelho IAC 44 & Cilíndrico & Média & Médio & Médio & Horizontal & Alta & Baixa & Média \\
\hline Catuaí Vermelho IAC 46 & Cilíndrico & Média & Médio & Médio & Horizontal & Alta & Baixa & Média \\
\hline Catuaí Vermelho IAC 81 & Cilíndrico & Média & Médio & Médio & Horizontal & Alta & Baixa & Média \\
\hline Catuaí Vermelho IAC 99 & Cilíndrico & Média & Médio & Médio & Horizontal & Alta & Baixa & Média \\
\hline Catuaí Vermelho IAC 144 & Cilíndrico & Média & Médio & Médio & Horizontal & Alta & Baixa & Média \\
\hline Icatu Amarelo IAC 2944-6 & Cilíndrico & Alta & Grande & Longo & Horizontal & Média & Baixa & Média \\
\hline Icatu Precoce IAC 3282 & Cilíndrico & Alta & Grande & Longo & Horizontal & Média & Baixa & Média \\
\hline Icatu Vermelho IAC 2945 & Cilíndrico & Alta & Grande & Longo & Horizontal & Média & Baixa & Média \\
\hline Icatu Vermelho IAC 4040 & Cilíndrico & Alta & Grande & Longo & Horizontal & Média & Baixa & Média \\
\hline Icatu Vermelho IAC 4042 & Cilíndrico & Alta & Grande & Longo & Horizontal & Média & Baixa & Média \\
\hline Icatu Vermelho IAC 4045 & Cilíndrico & Alta & Grande & Longo & Horizontal & Média & Baixa & Média \\
\hline Icatu Vermelho IAC 4046 & Cilíndrico & Alta & Grande & Longo & Horizontal & Média & Baixa & Média \\
\hline Mundo Novo IAC 376-4 & Cilíndrico & Muito alta & Muito grande & Longo & Horizontal & Média & Baixa & Média \\
\hline Mundo Novo IAC 379-19 & Cilíndrico & Muito alta & Muito grande & Longo & Horizontal & Média & Baixa & Média \\
\hline Mundo Novo IAC 388-17 & Cilíndrico & Muito alta & Muito grande & Longo & Horizontal & Média & Baixa & Média \\
\hline Mundo Novo IAC 501 & Cilíndrico & Muito alta & Muito grande & Longo & Horizontal & Média & Baixa & Média \\
\hline Mundo Novo IAC 515 & Cilíndrico & Muito alta & Muito grande & Longo & Horizontal & Média & Baixa & Média \\
\hline Ouro Verde IAC H5010-5 & Cilíndrico & Média & Médio & Médio & Horizontal & Alta & Baixa & Média \\
\hline Obatã IAC 1669-20 & Cilíndrico & Baixa & Pequeno & Curto & Horizontal & Alta & Baixa & Média \\
\hline Tupi IAC 1669-33 & Cilíndrico & Baixa & Pequeno & Curto & Horizontal & Alta & Baixa & Média \\
\hline
\end{tabular}




\subsection{Folhas}

A descrição das cultivares com base em características das folhas jovens e adultas é apresentada na tabela 4. Seis das dez características avaliadas foram bastante homogêneas e pouco eficientes na diferenciação das 29 cultivares de C. arabica utilizadas no estudo. Pode-se dizer que esse conjunto de cultivares apresenta, sem qualquer variação, folhas adultas de coloração verde-escura, formato elíptico, bordas onduladas, nervuras secundárias de pequena profundidade e domácias glabras e parcialmente desenvolvidas.

O tamanho das folhas, caracterizado pelo comprimento e largura máxima da lâmina foliar, apresentou apenas pequena variação entre o germoplasma avaliado. Folhas da cultivar Bourbon Amarelo IAC J18 são mais curtas e estreitas, enquanto as folhas das cultivares Obatã IAC 1669-20 e Tupi IAC 1669-33 são longas e largas, certamente em função do parentesco com a espécie $C$. canephora.

As cultivares Icatu Amarelo IAC 2944-6, Icatu Precoce IAC 3282 e do grupo Icatu Vermelho, também obtidas a partir da hibridação entre as espécies $C$. arabica e $C$. canephora, apresentaram, assim como as cultivares dos grupos Acaiá, Catuaí Vermelho, Catuaí Amarelo, Mundo Novo e Ouro Verde IAC H5010-5, folhas de tamanho médio.

A cor das folhas jovens, determinada pela expressão de um gene com dominância incompleta (KRUG e CARVAlHo, 1942), é importante descritor para as cultivares do grupo Mundo Novo. Por meio dela, foi possível separar as cultivares Mundo Novo IAC 3764 e Mundo Novo IAC 388-17, que possuem brotos verdes $(b r b r)$, das cultivares Mundo Novo IAC 501, Mundo Novo IAC 515 e Mundo Novo IAC 379-19, com folhas novas de coloração bronze $(\mathrm{Br} \mathrm{Br})$.

As cultivares Icatu Amarelo IAC 2944-6, Icatu Precoce IAC 3282 e as do grupo Icatu Vermelho não possuem essa característica fixada e são de difícil discriminação partindo dessa característica. Da mesma maneira, a cultivar Bourbon Amarelo IAC J18 que tem sua origem mais provável no cruzamento natural das cultivares Amarelo de Botucatu $(\mathrm{Br} \mathrm{Br}$ ) e Bourbon Vermelho (br br), também segrega para a coloração das folhas jovens (CARVALHo et al., 1957).

As cultivares Obatã IAC 1669-20 e Tupi IAC 1669-33 apresentam folhas com forte intensidade de ondulação, semelhantes às de cultivares de $C$. canephora (CHEVALIER, 1947); o mesmo não ocorre com as cultivares Icatu Amarelo IAC 2944-6, Icatu Precoce IAC 3282 e aquelas do grupo Icatu Vermelho, também obtidas a partir de cruzamentos de C. arabica com essa espécie diplóide.

\subsection{Flores}

As características das flores foram pouco eficientes na discriminação do germoplasma. Somente o número de inflorescência por axila e o número de flores por inflorescência apresentaram poucas variações (Tabela 5). Como a produção de frutos é definida por uma equação complexa, cujas duas características têm um peso bastante importante (MônAco et al., 1965), e as cultivares são selecionadas, em princípio, pelo nível de produtividade das plantas, a classificação alta atribuída a todas elas era bastante previsível.

Apenas a cultivar Bourbon Amarelo IAC J18 apresentou índice médio para essas características. Convém salientar que se trata da mais antiga das cultivares avaliadas neste estudo, e que um ganho significativo de produção foi acumulado no desenvolvimento das cultivares mais recentes (CARVALHO et al., 1964).

Todas as cultivares de C. arabica apresentaram pólen fértil, sendo autocompatíveis, embora a taxa de polinização cruzada varie ligeiramente, sobretudo nas cultivares do grupo Icatu Vermelho, Icatu Amarelo IAC 2944-6, Icatu Precoce IAC 3282, Tupi IAC 166933 e Obatã IAC 1669-20 que apresentam origem interespecífica (FAZUOLI, 1991; FAZUOLI et al., 2000).

\subsection{Frutos}

Os dados referentes às características dos frutos encontram-se na tabela 5. Os frutos das cultivares de C. arabica possuem formato oblongo e não apresentam sépalas desenvolvidas ( $s d s d$ ), como as presentes na variedade botânica denominada goiaba (KRUG e Carvalho, 1946). Nas cultivares comerciais ( $S d S d)$ as sépalas são reduzidas a dentículos bem pouco aparentes nos frutos maduros (CARVALHO et al., 1991).

Por sua vez, a cor dos frutos no cafeeiro é determinada pela expressão de um gene recessivo de dominância incompleta denominado xanthocarpa (Krug e Carvalho, 1940). Plantas xc xc produzem frutos de exocarpo amarelo, enquanto em plantas de constituição genética $X_{c} X_{c}$, o exocarpo dos frutos é de coloração vermelha. Embora apenas duas classes de cultivares possam ser estabelecidas a partir dessa característica, a cor dos frutos foi considerada um importante descritor por permitir a distinção entre as cultivares dos grupos Catuaí Vermelho e Catuaí Amarelo, assim como, dos grupos Icatu Vermelho e Icatu Amarelo.

Os frutos das cultivares avaliadas apresentam, em geral, tamanho médio. Apenas as cultivares do grupo Acaiá e Bourbon Amarelo IAC J18 têm, respectivamente, frutos de tamanho grande e pequeno. 
Tabela 4. Características qualitativas das folhas de diferentes cultivares de C. arabica

\begin{tabular}{|c|c|c|c|c|c|c|c|c|c|c|}
\hline \multirow[b]{2}{*}{ Cultivar } & \multirow[b]{2}{*}{ Comprimento } & \multirow[b]{2}{*}{ Largura } & \multirow[b]{2}{*}{ Forma } & \multicolumn{2}{|c|}{ Cor das folhas } & \multirow{2}{*}{$\begin{array}{l}\text { Ondulação } \\
\text { das bordas }\end{array}$} & \multirow{2}{*}{$\begin{array}{l}\text { Intensidade } \\
\text { de ondulação }\end{array}$} & \multirow{2}{*}{$\begin{array}{l}\text { Profundida da } \\
\text { nervura secundária }\end{array}$} & \multicolumn{2}{|c|}{ Domácias } \\
\hline & & & & Jovens & Adultas & & & & Desenvolvimento & Pubescência \\
\hline Acaiá IAC 474-4 & Médio & Média & Elíptica & Bronze & Verde-escura & Presente & Média & Baixa & Parcial & Ausente \\
\hline Acaiá IAC 474-16 & Médio & Média & Elíptica & Bronze & Verde-escura & Presente & Média & Baixa & Parc. desenv. & Ausente \\
\hline Acaiá IAC 474-19 & Médio & Média & Elíptica & Bronze & Verde-escura & Presente & Média & Baixa & Parc. desenv. & Ausente \\
\hline Bourbon Amarelo IAC J18 & Curto & Estreita & Elíptica & Verde e Bronze & Verde-escura & Presente & Média & Baixa & Parc. desenv. & Ausente \\
\hline Catuaí Amarelo IAC 47 & Médio & Média & Elíptica & Verde & Verde-escura & Presente & Média & Baixa & Parc. desenv. & Ausente \\
\hline Catuaí Amarelo IAC 62 & Médio & Média & Elíptica & Verde & Verde-escura & Presente & Média & Baixa & Parc. desenv. & Ausente \\
\hline Catuaí Amarelo IAC 74 & Médio & Média & Elíptica & Verde & Verde-escura & Presente & Média & Baixa & Parc. desenv. & Ausente \\
\hline Catuaí Amarelo IAC 86 & Médio & Média & Elíptica & Verde & Verde-escura & Presente & Média & Baixa & Parc. desenv. & Ausente \\
\hline Catuaí Amarelo IAC 100 & Médio & Média & Elíptica & Verde & Verde-escura & Presente & Média & Baixa & Parc. desenv. & Ausente \\
\hline Catuaí Vermelho IAC 44 & Médio & Média & Elíptica & Verde & Verde-escura & Presente & Média & Baixa & Parc. desenv. & Ausente \\
\hline Catuaí Vermelho IAC 46 & Médio & Média & Elíptica & Verde & Verde-escura & Presente & Média & Baixa & Parc. desenv. & Ausente \\
\hline Catuaí Vermelho IAC 81 & Médio & Média & Elíptica & Verde & Verde-escura & Presente & Média & Baixa & Parc. desenv. & Ausente \\
\hline Catuaí Vermelho IAC 99 & Médio & Média & Elíptica & Verde & Verde-escura & Presente & Média & Baixa & Parc. desenv. & Ausente \\
\hline Catuaí Vermelho IAC 144 & Médio & Média & Elíptica & Verde & Verde-escura & Presente & Média & Baixa & Parc. desenv. & Ausente \\
\hline Icatu Amarelo IAC 2944-6 & Médio & Média & Elíptica & Verde e Bronze & Verde-escura & Presente & Média & Baixa & Parc. desenv. & Ausente \\
\hline Icatu Precoce IAC 3282 & Médio & Média & Elíptica & Verde e Bronze & Verde-escura & Presente & Média & Baixa & Parc. desenv. & Ausente \\
\hline Icatu Vermelho IAC 2945 & Médio & Média & Elíptica & Verde e Bronze & Verde-escura & Presente & Média & Baixa & Parc. desenv. & Ausente \\
\hline Icatu Vermelho IAC 4040 & Médio & Média & Elíptica & Verde e Bronze & Verde-escura & Presente & Média & Baixa & Parc. desenv. & Ausente \\
\hline Icatu Vermelho IAC 4042 & Médio & Média & Elíptica & Verde e Bronze & Verde-escura & Presente & Média & Baixa & Parc. desenv. & Ausente \\
\hline Icatu Vermelho IAC 4045 & Médio & Média & Elíptica & Verde e Bronze & Verde-escura & Presente & Média & Baixa & Parc. desenv. & Ausente \\
\hline Icatu Vermelho IAC 4046 & Médio & Média & Elíptica & Verde e Bronze & Verde-escura & Presente & Média & Baixa & Parc. desenv. & Ausente \\
\hline Mundo Novo IAC 376-4 & Médio & Média & Elíptica & Verde & Verde-escura & Presente & Média & Baixa & Parc. desenv. & Ausente \\
\hline Mundo Novo IAC 379-19 & Médio & Média & Elíptica & Bronze & Verde-escura & Presente & Média & Baixa & Parc. desenv. & Ausente \\
\hline Mundo Novo IAC 388-17 & Médio & Média & Elíptica & Verde & Verde-escura & Presente & Média & Baixa & Parc. desenv. & Ausente \\
\hline Mundo Novo IAC 501 & Médio & Média & Elíptica & Bronze & Verde-escura & Presente & Média & Baixa & Parc. desenv. & Ausente \\
\hline Mundo Novo IAC 515 & Médio & Média & Elíptica & Bronze & Verde-escura & Presente & Média & Baixa & Parc. desenv. & Ausente \\
\hline Ouro Verde IAC H5010-5 & Médio & Média & Elíptica & Bronze & Verde-escura & Presente & Média & Baixa & Parc. desenv. & Ausente \\
\hline Obatã IAC 1669-20 & Longo & Larga & Elíptica & Verde & Verde-escura & Presente & Forte & Baixa & Parc. desenv. & Ausente \\
\hline Tupi IAC 1669-33 & Longo & Larga & Elíptica & Bronze & Verde-escura & Presente & Forte & Baixa & Parc. desenv. & Ausente \\
\hline
\end{tabular}


Tabela 5. Características qualitativas das flores e frutos de diferentes cultivares de C. arabica

\begin{tabular}{|c|c|c|c|c|c|c|c|c|c|}
\hline \multirow[b]{2}{*}{ Cultivar } & \multicolumn{4}{|c|}{ Flor } & \multicolumn{5}{|c|}{ Fruto } \\
\hline & $\begin{array}{l}\text { Inflorescências } \\
\text { por axila }\end{array}$ & $\begin{array}{c}\text { Flores por } \\
\text { inflorescência }\end{array}$ & Pólen & Compatibilidade & Tamanho & Formato & Cor & Sépala & $\begin{array}{c}\text { Grau de } \\
\text { aderência ao ramo }\end{array}$ \\
\hline Acaiá IAC 474-4 & Alta & Alta & Fértil & Autocompatível & Grande & Oblongo & Vermelho-média & Ausente & Médio \\
\hline Acaiá IAC 474-16 & Alta & Alta & Fértil & Autocompatível & Grande & Oblongo & Vermelho-média & Ausente & Médio \\
\hline Acaiá IAC 474-19 & Alta & Alta & Fértil & Autocompatível & Grande & Oblongo & Vermelho-média & Ausente & Médio \\
\hline Bourbon Amarelo IAC J18 & Média & Média & Fértil & Autocompatível & Pequeno & Oblongo & Amarela & Ausente & Médio \\
\hline Catuaí Amarelo IAC 47 & Alta & Alta & Fértil & Autocompatível & Médio & Oblongo & Amarela & Ausente & Médio \\
\hline Catuaí Amarelo IAC 62 & Alta & Alta & Fértil & Autocompatível & Médio & Oblongo & Amarela & Ausente & Médio \\
\hline Catuaí Amarelo IAC 74 & Alta & Alta & Fértil & Autocompatível & Médio & Oblongo & Amarela & Ausente & Médio \\
\hline Catuaí Amarelo IAC 86 & Alta & Alta & Fértil & Autocompatível & Médio & Oblongo & Amarela & Ausente & Médio \\
\hline Catuaí Amarelo IAC 100 & Alta & Alta & Fértil & Autocompatível & Médio & Oblongo & Amarela & Ausente & Médio \\
\hline Catuaí Vermelho IAC 44 & Alta & Alta & Fértil & Autocompatível & Médio & Oblongo & Vermelho-média & Ausente & Médio \\
\hline Catuaí Vermelho IAC 46 & Alta & Alta & Fértil & Autocompatível & Médio & Oblongo & Vermelho-média & Ausente & Médio \\
\hline Catuaí Vermelho IAC 81 & Alta & Alta & Fértil & Autocompatível & Médio & Oblongo & Vermelho-média & Ausente & Médio \\
\hline Catuaí Vermelho IAC 99 & Alta & Alta & Fértil & Autocompatível & Médio & Oblongo & Vermelho-média & Ausente & Médio \\
\hline Catuaí Vermelho IAC 144 & Alta & Alta & Fértil & Autocompatível & Médio & Oblongo & Vermelho-média & Ausente & Médio \\
\hline Icatu Amarelo IAC 2944-6 & Alta & Alta & Fértil & Autocompatível & Médio & Oblongo & Amarela & Ausente & Alto \\
\hline Icatu Precoce IAC 3282 & Alta & Alta & Fértil & Autocompatível & Médio & Oblongo & Amarela & Ausente & Alto \\
\hline Icatu Vermelho IAC 2945 & Alta & Alta & Fértil & Autocompatível & Médio & Oblongo & Vermelho-média & Ausente & Alto \\
\hline Icatu Vermelho IAC 4040 & Alta & Alta & Fértil & Autocompatível & Médio & Oblongo & Vermelho-média & Ausente & Alto \\
\hline Icatu Vermelho IAC 4042 & Alta & Alta & Fértil & Autocompatível & Médio & Oblongo & Vermelho-média & Ausente & Alto \\
\hline Icatu Vermelho IAC 4045 & Alta & Alta & Fértil & Autocompatível & Médio & Oblongo & Vermelho-média & Ausente & Alto \\
\hline Icatu Vermelho IAC 4046 & Alta & Alta & Fértil & Autocompatível & Médio & Oblongo & Vermelho-média & Ausente & Alto \\
\hline Mundo Novo IAC 376-4 & Alta & Alta & Fértil & Autocompatível & Médio & Oblongo & Vermelho-média & Ausente & Alto \\
\hline Mundo Novo IAC 379-19 & Alta & Alta & Fértil & Autocompatível & Médio & Oblongo & Vermelho-média & Ausente & Médio \\
\hline Mundo Novo IAC 388-17 & Alta & Alta & Fértil & Autocompatível & Médio & Oblongo & Vermelho-média & Ausente & Médio \\
\hline Mundo Novo IAC 501 & Alta & Alta & Fértil & Autocompatível & Médio & Oblongo & Vermelho-média & Ausente & Médio \\
\hline Mundo Novo IAC 515 & Alta & Alta & Fértil & Autocompatível & Médio & Oblongo & Vermelho-média & Ausente & Médio \\
\hline Ouro Verde IAC H5010-5 & Alta & Alta & Fértil & Autocompatível & Médio & Oblongo & Vermelho-média & Ausente & Médio \\
\hline Obatã IAC 1669-20 & Alta & Alta & Fértil & Autocompatível & Médio & Oblongo & Vermelho-média & Ausente & Alto \\
\hline Tupi IAC 1669-33 & Alta & Alta & Fértil & Autocompatível & Médio & Oblongo & Vermelho-média & Ausente & Alto \\
\hline
\end{tabular}


A aderência dos frutos aos ramos tem fundamental importância para a colheita dos frutos, principalmente para a colheita mecânica. Essa característica separa as cultivares em apenas dois grupos: alta, para as cultivares de origem interespecífica como Obatã IAC 1669-20, Tupi IAC 1669-33, Icatu Amarelo IAC 2944-6, Icatu Precoce IAC 3282 e as do grupo Icatu Vermelho, e média para as demais. Naquelas cultivares, a queda de frutos maduros ou secos é bastante reduzida. Se essa característica pode resultar em menor rendimento da mão-de-obra na colheita (FAzUOLi et al., 2001), frutos que permanecem por mais tempo na planta têm maior potencial para a produção de cafés de qualidade.

\subsection{Sementes}

O tamanho das sementes tem também importante componente ambiental, e pode variar em função do local de cultivo, das condições de manejo e climáticas presentes durante o ciclo produtivo anual (Tabela 6). No entanto, em condições uniformes, as cultivares do grupo Acaiá apresentam sementes maiores e a cultivar Bourbon Amarelo IAC J18 possui sementes menores que as demais cultivares avaliadas, tanto em relação ao comprimento quanto à largura. Todas as cultivares apresentaram sementes de espessura média, endosperma de coloração verde, película prateada clara e ligeiramente aderida ao endosperma e médio teor de cafeína. Quantitativamente, esse teor varia em torno de $1,0 \%$ na espécie C. arabica (Ashirhara e CROZIER, 2001).

A densidade dos grãos é uma característica de grande importância para as cultivares comerciais de café, uma vez que apresenta relação inversa com o número de sementes por unidade de massa, guardando estreita correlação com o tamanho - comprimento, largura e espessura - das sementes. Observa-se, no entanto, que a massa de cem sementes é bastante uniforme entre as cultivares avaliadas, sendo considerada alta apenas para as cultivares do grupo Acaiá e média para as demais (Tabela 6).

\subsection{Características agronômicas}

A duração do ciclo de maturação (Tabela 6) período compreendido entre a antese e a maturação completa dos frutos - contribui eficazmente para a distinção de algumas cultivares, como Icatu Amarelo IAC 2944-6 e Icatu Precoce IAC 3282 ou Obatã IAC 166920 e Tupi IAC 1669-33. No primeiro caso, ambas têm porte alto, são resistentes a $H$. vastatrix e produzem frutos de coloração amarela e segregam para a cor das folhas jovens. No entanto, a cultivar Icatu Precoce IAC 3282 tem, como o próprio nome indica, ciclo mais curto de maturação do que a cultivar Icatu Amarelo IAC 2944-6. Situação bastante parecida é observada em relação às cultivares Tupi IAC 1669-33 e Obatã IAC 1669-20: ambas têm porte baixo, são resistentes ao agente da ferrugem e produzem frutos com exocarpo vermelho. Todavia, a cultivar Tupi IAC 1669-33 é mais precoce do que a Obatã IAC 1669-20.

Convém ressaltar que a cor das folhas jovens cumpre a mesma função do ciclo de maturação para distinguir as duas cultivares, com a vantagem de permitir a identificação ainda na fase de muda em viveiro.

Com relação ao período até a primeira produção após o plantio, ou precocidade produtiva (Tabela 6), as cultivares dos grupos Acaiá e Mundo Novo foram classificadas como tardias; Bourbon Amarelo IAC J18, média e as demais, precoces. Sua utilização, entretanto, é pouco útil para identificar as cultivares de cada um dos grupos.

Este estudo foi desenvolvido visando à identificação dos descritores mínimos eficientes na caracterização de cultivares de cafeeiros.

A opção pela utilização de cultivares selecionadas pelo IAC deve-se, sobretudo à certificação de origem genética do material avaliado e também à sua representatividade no cenário agrícola nacional, uma vez que cerca de $90 \%$ do parque cafeeiro de $C$. arabica é composto por cultivares selecionadas pelo Instituto Agronômico (IAC), de Campinas.

Embora parte importante das 38 características qualitativas utilizadas nesse estudo tenha revelado certa eficácia na diferenciação de cultivares de C. arabica, seis delas - altura das plantas, resistência a $H$. vastatrix, cor dos frutos, ciclo de maturação dos frutos, cor das folhas jovens e diâmetro da copa - foram selecionadas para a rápida discriminação dos diferentes grupos de cultivares e em alguns casos, na distinção entre cultivares de um mesmo grupo (Tabela 7). À exceção do ciclo de maturação e diâmetro da copa a expressão das demais características sofre pouco influência ambiental e parte delas pode ser avaliada ainda na fase de mudas em viveiro.

Em síntese, os descritores avaliados podem ser considerados eficientes na identificação de grupos distintos de cultivares, mas pouco úteis na discriminação entre cultivares de um mesmo grupo, como Catuaí Vermelho, Catuaí Amarelo e Icatu Vermelho. Quanto às cultivares do grupo Mundo Novo, o descritor cor das folhas novas, pode separá-las em dois grupos: Mundo Novo IAC 376 e Mundo Novo IAC 388-17 - brotos verdes - e as demais cultivares - brotos bronzes. 
Tabela 6. Características qualitativas das sementes e características agronômicas de diferentes cultivares de $C$. arabica

\begin{tabular}{|c|c|c|c|c|c|c|c|c|c|c|c|}
\hline Cultivar & Comprimento & Largura & Espessura & $\begin{array}{c}\text { Cor } \\
\text { do } \\
\text { endosperma }\end{array}$ & $\begin{array}{c}\text { Tonalidade } \\
\text { da película } \\
\text { prateada }\end{array}$ & $\begin{array}{c}\text { Aderência } \\
\text { da película } \\
\text { prateada }\end{array}$ & $\begin{array}{c}\text { Teor } \\
\text { de } \\
\text { cafeíena }\end{array}$ & $\begin{array}{c}\text { Massa } \\
\text { de cem } \\
\text { sementes }\end{array}$ & $\begin{array}{c}\text { Ciclo } \\
\text { de } \\
\text { maturação }\end{array}$ & $\begin{array}{c}\text { Ciclo } \\
{\text { até } 1 .^{\text {a }}}^{\text {produção }}\end{array}$ & $\begin{array}{l}\text { Resistência } \\
\text { à } \\
\text { H. vastatrix }\end{array}$ \\
\hline Acaiá IAC 474-4 & Longo & Estreita & Média & Verde & Clara & Fraca & Médio & Alta & Precoce & Tardio & Ausente \\
\hline Acaiá IAC 474-16 & Longo & Estreita & Média & Verde & Clara & Fraca & Médio & Alta & Precoce & Tardio & Ausente \\
\hline Acaiá IAC 474-19 & Longo & Estreita & Média & Verde & Clara & Fraca & Médio & Alta & Precoce & Tardio & Ausente \\
\hline Bourbon Amarelo IAC J18 & Curto & Larga & Média & Verde & Clara & Fraca & Médio & Média & Precoce & Médio & Ausente \\
\hline Catuaí Amarelo IAC 47 & Curto & Larga & Média & Verde & Clara & Fraca & Médio & Média & Tardio & Precoce & Ausente \\
\hline Catuaí Amarelo IAC 62 & Curto & Larga & Média & Verde & Clara & Fraca & Médio & Média & Tardio & Precoce & Ausente \\
\hline Catuaí Amarelo IAC 74 & Curto & Larga & Média & Verde & Clara & Fraca & Médio & Média & Tardio & Precoce & Ausente \\
\hline Catuaí Amarelo IAC 86 & Curto & Larga & Média & Verde & Clara & Fraca & Médio & Média & Tardio & Precoce & Ausente \\
\hline Catuaí Amarelo IAC 100 & Curto & Larga & Média & Verde & Clara & Fraca & Médio & Média & Tardio & Precoce & Ausente \\
\hline Catuaí VermelhoIAC 44 & Curto & Larga & Média & Verde & Clara & Fraca & Médio & Média & Tardio & Precoce & Ausente \\
\hline Catuaí Vermelho IAC 46 & Curto & Larga & Média & Verde & Clara & Fraca & Médio & Média & Tardio & Precoce & Ausente \\
\hline Catuaí Vermelho IAC 81 & Curto & Larga & Média & Verde & Clara & Fraca & Médio & Média & Tardio & Precoce & Ausente \\
\hline Catuaí Vermelho IAC 99 & Curto & Larga & Média & Verde & Clara & Fraca & Médio & Média & Tardio & Precoce & Ausente \\
\hline Catuaí Vermelho IAC 144 & Curto & Larga & Média & Verde & Clara & Fraca & Médio & Média & Tardio & Precoce & Ausente \\
\hline Icatu Amarelo IAC 2944-6 & Curto & Larga & Média & Verde & Clara & Fraca & Médio & Média & Tardio & Precoce & Presente \\
\hline Icatu Precoce IAC 3282 & Curto & Larga & Média & Verde & Clara & Fraca & Médio & Média & Precoce & Precoce & Presente \\
\hline Icatu Vermelho IAC 2945 & Curto & Larga & Média & Verde & Clara & Fraca & Médio & Média & Tardio & Precoce & Presente \\
\hline Icatu Vermelho IAC 4040 & Curto & Larga & Média & Verde & Clara & Fraca & Médio & Média & Tardio & Precoce & Presente \\
\hline Icatu Vermelho IAC 4042 & Curto & Larga & Média & Verde & Clara & Fraca & Médio & Média & Tardio & Precoce & Presente \\
\hline Icatu Vermelho IAC 4045 & Curto & Larga & Média & Verde & Clara & Fraca & Médio & Média & Tardio & Precoce & Presente \\
\hline Icatu Vermelho IAC 4046 & Curto & Larga & Média & Verde & Clara & Fraca & Médio & Média & Tardio & Precoce & Presente \\
\hline Mundo Novo IAC 376-4 & Médio & Média & Média & Verde & Clara & Fraca & Médio & Média & Médio & Tardio & Ausente \\
\hline Mundo Novo IAC 379-19 & Médio & Média & Média & Verde & Clara & Fraca & Médio & Média & Médio & Tardio & Ausente \\
\hline Mundo Novo IAC 388-17 & Médio & Média & Média & Verde & Clara & Fraca & Médio & Média & Médio & Tardio & Ausente \\
\hline Mundo Novo IAC 501 & Médio & Média & Média & Verde & Clara & Fraca & Médio & Média & Médio & Tardio & Ausente \\
\hline Mundo Novo IAC 515 & Médio & Média & Média & Verde & Clara & Fraca & Médio & Média & Médio & Tardio & Ausente \\
\hline Ouro Verde IAC H5010-5 & Curto & Larga & Média & Verde & Clara & Fraca & Médio & Média & Tardio & Precoce & Ausente \\
\hline Obatã IAC 1669-20 & Curto & Larga & Média & Verde & Clara & Fraca & Médio & Média & Tardio & Precoce & Presente \\
\hline Tupi IAC 1669-33 & Curto & Larga & Média & Verde & Clara & Fraca & Médio & Média & Precoce & Precoce & Presente \\
\hline
\end{tabular}




\begin{tabular}{|c|c|c|c|c|c|c|}
\hline Altura das plantas & $\begin{array}{l}\text { Resistência a } \\
\text { Hemileia vastatrix }\end{array}$ & Cor dos frutos & Ciclo de maturação & Cor das folhas jovens & Cultivares & Grupo de cultivares \\
\hline \multirow{5}{*}{$\begin{array}{l}\text { Baixa ou Média } \\
\qquad(C t C t)\end{array}$} & \multirow{2}{*}{ Resistente } & \multirow{2}{*}{$\begin{array}{l}\text { Vermelha } \\
\qquad(X c X c)\end{array}$} & Precoce & $\begin{array}{r}\text { Bronze } \\
(\mathrm{Br} \mathrm{Br})\end{array}$ & Tupi IAC 1669-33 & Tupi \\
\hline & & & Tardio & $\begin{array}{l}\text { Verde } \\
(b r b r)\end{array}$ & Obatã IAC 1669-20 & Obatã \\
\hline & \multirow{3}{*}{ Suscetível } & \multirow{2}{*}{$\begin{array}{l}\text { Vermelha } \\
\qquad(X c X c)\end{array}$} & Tardio & $\begin{array}{l}\text { Bronze } \\
(B r B r)\end{array}$ & Ouro Verde IAC H5010-5 & Ouro Verde \\
\hline & & & Tardio & $\begin{array}{l}\text { Verde } \\
(b r b r)\end{array}$ & $\begin{array}{c}\text { Catuaí Vermelho IAC 44, Catuaí Vermelho IAC 46, } \\
\text { Catuaí Vermelho IAC 81, Catuaí Vermelho IAC } 99 \\
\text { e Catuaí Vermelho IAC } 144\end{array}$ & Catuaí Vermelho \\
\hline & & $\begin{array}{l}\text { Amarela } \\
\qquad(x c x c)\end{array}$ & Tardio & $\begin{array}{l}\text { Verde } \\
(b r b r)\end{array}$ & $\begin{array}{c}\text { Catuaí Amarelo IAC 47, Catuaí Amarelo IAC 62, } \\
\text { Catuaí Amarelo IAC 74, Catuaí Amarelo IAC } 86 \\
\text { e Catuaí Amarelo IAC } 100\end{array}$ & Catuaí Amarelo \\
\hline \multirow{7}{*}{$\begin{array}{l}\text { Alta ou Muita Alta } \\
\qquad(c t c t)\end{array}$} & \multirow{3}{*}{ Resistente } & $\begin{array}{l}\text { Vermelha } \\
(X c X c)\end{array}$ & Tardio & $\begin{array}{l}\text { Verde e Bronze } \\
(b r b r) \text { e }(B r B r)\end{array}$ & $\begin{array}{c}\text { Icatu Vermelho IAC 2945, Icatu Vermelho IAC } 4040 \text {, } \\
\text { Icatu Vermelho IAC 4042, Icatu VermelhoIAC } 4045 \\
\text { e Icatu Vermelho }\end{array}$ & Icatu Vermelho \\
\hline & & \multirow{2}{*}{$\begin{array}{l}\text { Amarela } \\
\qquad(x c x c)\end{array}$} & Precoce & $\begin{array}{l}\text { Verde e Bronze } \\
(b r b r) \text { e }(B r B r)\end{array}$ & IAC 4046 Icatu Precoce IAC 3282 & Icatu Precoce \\
\hline & & & Tardio & $\begin{array}{l}\text { Verde e Bronze } \\
(b r b r) \text { e }(\mathrm{Br} B r)\end{array}$ & Icatu Amarelo IAC 2944-6 & Icatu Amarelo \\
\hline & \multirow{4}{*}{ Suscetível } & \multirow{3}{*}{$\begin{array}{l}\text { Vermelha } \\
\qquad(X c X c)\end{array}$} & Precoce & $\begin{array}{l}\text { Bronze } \\
(\mathrm{Br} B r)\end{array}$ & Acaiá IAC 474-4, Acaiá IAC 474-16 e Acaiá IAC 474-19 & Acaiá \\
\hline & & & \multirow{2}{*}{ Tardio } & $\begin{array}{l}\text { Verde } \\
(b r b r)\end{array}$ & Mundo Novo IAC 376-4 e Mundo Novo IAC 388-17 & Mundo Novo \\
\hline & & & & $\begin{array}{l}\text { Bronze } \\
(\mathrm{Br} \mathrm{Br})\end{array}$ & $\begin{array}{l}\text { Mundo Novo IAC 379-19, Mundo Novo IAC } 501 \\
\text { e Mundo Novo IAC } 515\end{array}$ & Mundo Novo \\
\hline & & $\begin{array}{l}\text { Amarela } \\
(x c x c)\end{array}$ & Precoce & $\begin{array}{l}\text { Verde } \\
(b r b r)\end{array}$ & Bourbon Amarelo IAC J18 & Bourbon Amarelo \\
\hline
\end{tabular}


Embora o diâmetro da copa tenha sido considerado como "muito grande" para todas as cultivares do grupo Mundo Novo, a cultivar Mundo Novo IAC 388-17 tem diâmetro da copa 20\% maior que Mundo Novo IAC 376-4 e as demais cultivares do grupo.

Assim, propõe-se uma nova classe - extremamente grande - para essa característica na relação dos descritores oficiais para a proteção de cultivares de café, utilizando-se a cultivar Mundo Novo IAC 38817-8 como referência. Se o diâmetro da copa pode separar as cultivares Mundo Novo IAC 376 e Mundo Novo IAC 388-17, as cultivares Mundo Novo IAC 37919, Mundo Novo IAC 501 e Mundo Novo IAC 515 continuam agrupadas e de difícil identificação a partir dos descritores utilizados no estudo.

A utilização de marcadores moleculares ou de descritores bioquímicos poderá auxiliar sobremaneira na identificação de diferenças entre cultivares semelhantes de um mesmo grupo ou entre as já registradas e as novas a serem protegidas.

Diversas pesquisas já vêm sendo desenvolvidas nessa direção e certamente poderão enriquecer qualitativamente a atual lista de descritores mínimos para a proteção de cultivares de cafeeiros.

\section{REFERÊNCIAS}

ANTHONY, F.; BERTRAND, B.; QUIROS, O.; WILCHES, A.; LASHERMES, P.; BERTHAUD, J.; CHARRIER, A. Genetic diversity of wild coffee (Coffea arabica L.) using molecular markers. Euphytica, Dordrecht, v.118, n.1, p.53-65, 2001.

ASHIHARA, H. AND CROZIER, A. Caffeine: a well known but little mentioned compound in plant science. Trends in Plant Science, London, v.6, n. 9, p.407-413, 2001.

BERTHAUD, J.; CHARRIER, A. Genetic resources of Coffea. In: CLARKE, R. J.; MACRAE, R. (Eds.) Coffee. London: Elsevier Applied Science, 1988. v. 4, p.1-42.

BRASIL. Secretaria de Apoio Rural e Cooperativismo. Serviço Nacional de Proteção de Cultivares. Portaria, n. ${ }^{\circ}$, de 17 de novembro de 2000. Diário Oficial [da República Federativa do Brasil], Brasília, n.223, p.6-7, 21 nov. 2000, Seção 1.

CARVALHO, A. Distribuição geográfica e classificação botânica do gênero Coffea com referência especial à espécie Arabica. Separata dos Boletins da Superintendência dos Serviços do Café, São Paulo, n.226-230, 1946.

CARVALHO, A.; ANTUNES FILHO, H.; MENDES, J.E.T.; LAZZARINI, W.; REIS, A.J.; ALOISI SOBRINHO, J.; MORAES, M.V.; NOGUEIRA, R.K.; ROCHA, T.R. Melhoramento do cafeeiro: XIII. Café Bourbon Amarelo. Bragantia, Campinas, v.16, n.28, p.411-455, 1957.
CARVALHO, A.; MEDINA FILHO, H.P.; FAZUOLI, L.C.; COSTA, W.M. Genética de Coffea: XXVI. Hereditariedade do porte reduzido do cultivar Caturra. Bragantia, Campinas, v.43, n.2, p. $443-458,1984$.

CARVALHO, A.; MEDINA FILHO, H.P.; FAZUOLI, L.C.; GUERREIRO FILHO, O.; LIMA, M.M.A. Aspectos genéticos do cafeeiro. Revista Brasileira de Genética, v.14, n.1, p.135$183,1991$.

CARVALHO, A.; MÔNACO, L. C.; CAMPANA, M. P. Melhoramento do cafeeiro XXVII Experimentos de seleções regionais de Jaú. Bragantia, Campinas, v.23, p.129-142, 1964.

CARVALHO, A.; MÔNACO, L.C. Transferência do fator caturra para o cultivar Mundo Novo de Coffea arabica. Bragantia, Campinas, v.31, p.379-399, 1972.

CARVALHO, A.; MÔNACO, L. C.; FAZUOLI, L. C.; COSTA, W. M.; MEDINA FILHO, H. P. Variabilidade na produção em progênies do cafeeiro "Mundo Novo". Bragantia, Campinas, v.43, n.2, p.509-517, 1984.

CHEVALIER, A. Lés caféiers du globe: III. Systhematique des caféiers, maladies et insects nuisibles. Fascicule III. Paris: Lechevalier, 1947. 356p. (Encyclopedie biologique, 28)

FAZUOLI, L. C. Genética e melhoramento do cafeeiro. In: RENA, A. B.; MALAVOLTA, E.; ROCHA, M.; YAMADA, T. Cultura do cafeeiro. Piracicaba: Potafós, 1986. p.87-113.

FAZUOLI, L. C. Metodologia, critérios e resultados da seleção em progênies do café Icatu com resistência a Hemileia vastatrix. 1991. 322f. Tese (Doutorado em Ciências) - Universidade Estadual de Campinas.

FAZUOLI, L.C.; SILVAROLLA, M.B.; CAMARGO, C.E.O.; POMMER, C.V.; CHIAVEGATO, E.J.; DALL'ORTO, F.A.C.; NAGAI, H.; GODOY, I. J.; VEIGA, R.F.A. Descritores mínimos para o registro institucional de cultivares: Café. Campinas: Instituto Agronômico, 1994. 8p. (Documentos IAC, 46)

FAZUOLI, L. C.; VALARINI, V.; CONCEIÇÃO, A. S.; BERNARDI, J. A. Força de adesão de frutos de vários tipos de cafeeiro. In: CONGRESSO BRASILEIRO DE PESQUISAS CAFEEIRAS, 27., 2002, Uberaba. Resumos... Rio de Janeiro: MA/PROCAFÉ, 2001. p.117-118, 2001.

FAZUOLI, L.C; MEDINA FILHO, H.P.; GUERREIRO FILHO, O.; GONÇALVES, W.; SILVAROLLA, M.B.; GALLO, P.B. Cultivares de café IAC apropriadas para plantio adensado. Campinas: Instituto Agronômico de Campinas, 2000. (Fôlder)

IPGRI - International Plant Genetic Resources Institute. Descriptors for Coffee (Coffea spp. and Psilanthus spp.) Roma: IPGRI, 1996. 35p.

KRUG, C.A.; CARVALHO, A. Genética de Cofeea. V. Hereditariedade da coloração bronzeada das folhas novas de Coffea arabica L. Bragantia, Campinas, v.2, n.6, p.199-220, 1942.

KRUG, C. A.; CARVALHO, A. Genética de Coffea III. Hereditariedade da cor amarela dos frutos. Boletim Técnico do Instituto Agronômico do Estado, Campinas, v.82, p.1-16, figs.1-4, 1940. 
KRUG, C.A.; CARVALHO, A. Genética de Cofeea. X. Hereditariedade da ocorrência de sépalas desenvolvidas nas flores de Coffea arabica L. var. goiaba Taschdjian Bragantia, Campinas, v.6, p.251-264, 1946.

KRUG, C.A.; MENDES, J.E.T.; CARVALHO, A. Taxonomia de Coffea arabica L: Descrição das variedades e formas encontradas no Estado de São Paulo. Campinas: Instituto Agronômico, 1938. 57p. (Boletim Técnico, 62).
MÔNACO, L.C.; CARVALHO, A.; ROCHA, T.R. Melhoramento do cafeeiro: XXVIII. Experimento de seleções regionais em Mococa. Bragantia, Campinas, v.24, n.2, p.9-27, 1965. 